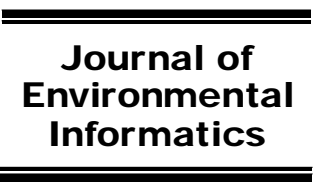

www.iseis.org/jei

\title{
Rapid Assessment Method for Eco-Water Deficit in Catchments
}

\author{
M. S. Zheng ${ }^{1}$, L. K. Ma ${ }^{1}$, T. H. Li ${ }^{1, *}$, and R. Huang ${ }^{1,2}$ \\ ${ }^{1}$ Key Laboratory of Water and Sediment Sciences, Ministry of Education, Department of Environmental Engineering, \\ Peking University, Beijing 100871, China \\ ${ }^{2}$ School of Environment and Energy, Peking University Shenzhen Graduate School, Shenzhen 518055, China
}

Received 16 January 2015; revised 12 March 2015; accepted 16 March 2015; published online 23 March 2015

\begin{abstract}
Eco-water deficit (EWD) is the difference between the eco-water required (EWR) for maintaining health of a given ecosystem and the actual eco-water used (EWU) by the same ecosystem. EWD is of significance for assessing the effectiveness of eco-water allocation and for sustainable water resources management. This paper proposes a rapid assessment method for catchment EWD. A framework is established to describe the concepts, characteristics and impact factors related to EWR for catchments containing various types of sub-ecosystems. The indicator of EWR (EWRI) of a catchment is defined as the sum of products between the weight representing the level of importance of each sub-ecosystem (sub-catchment) to EWR and its area percentage over the total area. By means of a series of processes of partition of spatial units, selection of reference units, classification of reference groups, determination of environmental variables, and identification of matching groups for the test units, EWDI, an indicator related to the relative degree of EWD severity of each test unit is calculated by subtracting the ratio of its observed and expected EWRI from one and then used to identify areas with most serious eco-water deficit. A case study is conducted in the Yanhe River catchment in north China based on land use data surveyed in 1990 and 2000. The results revealed that the south part of Ansai County, most of Baota District and the areas around Yan'an City experienced severe shortage of eco-water. The case study demonstrated the applicability of the rapid assessment method for EWD in practice.
\end{abstract}

Keywords: eco-water requirement, eco-water use, eco-water deficit, rapid assessment, Yanhe River catchment

\section{Introduction}

Natural ecosystems support crucial environmental functions and often provide services to human beings (Costanza et al., 1997; Cai et al., 2009a,b; Huang and Cao, 2011; Fan and Huang, 2012; Chen et al., 2018; Wang et al., 2018; Wu et al., 2018), including food production, climate modulation, water and soil conservation, etc (Deutschet et al., 2003). For natural ecosystems to remain sustainable, sufficient water must be available. This water, of a given quantity and quality which enables a natural ecosystem to maintain its health, is called the eco-water requirement (EWR). Conventional water resources management mainly concerned with human water supply needs, which inevitably lead to degradation of ecosystems and loss of their environmental functions and services critical to human development when water shortage occurs (Vorosmarty et al., 2000; Li et al., 2009; Li and Huang, 2009; Zhao et al., 2009, 2010; Shen et al., 2018). Therefore, the determination of EWR and allocation of eco-water use (EWU) are of primary significance, especially in regions where water

\footnotetext{
* Corresponding author. Tel.: + 861062753351 ; fax: +86 1062753351.

E-mail address: 1th@pku.edu.cn (T. H. Li).
}

ISSN: 1726-2135 print/1684-8799 online

(C) 2017 ISEIS All rights reserved. doi: 10.3808/jei.201500301 resources are scarce and serious water conflicts exist between human development activities and ecosystems.

The EWR of river ecosystems, also referred to as environmental flow (Thoms et al., 1996; Acreman and Ferguson, 2010) or minimum flow (Jowett, 1997), has been extensively studied from the late 19th century when people began to realize that the instream flow should be kept to a certain level to satisfy the growth requirements of indigenous fish species (Sheail, 1984). To the present day, a variety of approaches have been proposed for determining the EWR of river ecosystems (e.g. Tharme, 2003; Smakhtin, 2008; Pastor et al., 2014; Zalewski, 2015). These methods can be classified into five major categories: hydrology-based approaches, such as the Tennant approach (Tennant, 1976); range of variability approach (RVA) (Richter et al., 1997) and South African desktop reserve model (DRM) (Hughes et al., 2003); hydraulics-based approaches, such as the R2CROSS method (Mosely, 1982) and the wetted perimeter method (Gippel and Stewardson, 1998); ecology-based approaches, such as IFIM (Instream Flow Increment Methodology) (Stalnaker et al., 1994); ecologica land environmental function based approaches $(\mathrm{Ni}$ et al., 2002); and comprehensive and holistic methods such as the BBM (Building Block Method) approach (King and Louw, 1998).

Compared with the EWR of river ecosystems, very few studies have investigated the effect of EWR on other specific 
or integrated ecosystems in catchments, such as forests, grasslands, and scrublands. A reason for this is that river water is readily exploited by humans, and so is more susceptible to water-use. In China, EWR studies have recently been carried out considering various different kinds of ecosystems, such as EWR by rivers (Luo et al., 2004; Sun et al., 2015), vegetation (Zhao et al., 2007; Ye et al., 2010; Yu et al., 2015), wetlands (Jia and Luo, 2006; Cui et al., 2009). The inter-relations between hydrology and biota have been highlighted by eco-hydrologists (Falkenmark and Rockström, 2004), and so the properties of ecosystems must be fully considered in developing management tools for sustainable water resources utilization (Zalewski, 2000; Zalewski, 2015). Furthermore, traditional engineering-based water conservancy measures, such as dams and reservoirs, are being shifted to ecological ones, such as using forests to regulate the hydrological cycle (Liu, 1999). Active ecological rehabilitation, particularly with regard to vegetation, has become an effective measure for restoration of impaired habitats and for ensuring the mutual sustainability of human beings and ecosystems. Inevitably, this measure must be at the cost of a certain amount of the available water resource. Hence, there is an urgent need for EWR studies to be undertaken in terms of catchment ecosystems. In areas of water scarcity, it is of prime importance to estimate accurately the eco-water deficit, i.e. the EWD represented by the difference between EWR and EWU, and to identify those sub-catchments with the most severe EWD.

In practice, many difficulties are encountered in making a direct assessment of EWD: existing methods to calculate EWR still need to be improved, and data on EWU are hard to obtain because of the spatial and temporal variability of EWU and short study history on this issue, which makes the computation of EWD almost infeasible. Therefore, in this study, we will establish a method for assessing the severity of EWD. Owning to defining serval new indicators, model building idea learned from Rapid Bio-Assessment (RBA) and well-designed procedure, the method can bypass the direct calculation of an absolute value for EWD. The proposed method would use meteorological, topographical, hydrological and of land use data sets which usually are more convenient to obtain than the data required by absolute value calculation of EWD. Moreover, since the catchment is usually treated as the basic unit for water related issues, the results produced by the proposed method will be directly used for water management and ecosystem reconstruction practices.

A case study in the Yanhe River catchment, a tributary of the Yellow River, was conducted to demonstrate the method application. The catchment is located on the Loess Plateau in north China, which is characterized by very serious soil erosion, fragile environment, and scarcity of water resources. Studies of eco-water requirement (EWR) are very important for maintaining and improving the local ecosystem and achieving sustainable water resources utilization in this area.

\section{Rapid Assessment Method for Catchment EWD}

In order to undertake EWD assessment, it is necessary to divide the study area into proper spatial units, and evaluate an indicator which is proposed to determine the degree of severity of EWD. This section describes the key concepts underpinning EWD assessment, the grading and indicator of EWD, and then outlines the rapid assessment procedure.

\subsection{Key Concepts Underpinning EWD Rapid Assessment}

\section{(1) EWR in Catchment and Factors that Influence EWR}

A catchment ecosystem is a compound system with heterogenetic characteristics. It usually consists of different subecosystems such as rivers, lakes, marshes, forests, grasslands, urban areas, etc. Therefore, the catchment EWR should be determined by integrating the functions of these sub-ecosystems which may themselves be further divided into smaller units. EWR is a reflection of the intrinsic characteristics of an ecosystem. Therefore, the catchment EWR may be regarded as an indicator of the combined characteristics of the sub-ecosystems.

Meteorological, edaphic and terrain factors are major natural factors that affect the catchment EWR. Precipitation is the dominant water source for catchments. Solar radiation is not only the source of energy, but also the driving force of evapo-transpiration. Soil attributes like fertility, water content, viscosity and anti-erodibility have impacts on vegetation coverage and density, runoff and sediment concentration. Terrain factors influence the reallocation of water, energy and other materials. In addition, human activities (such as deforestation, urbanization, ground water exploitation, and pollution) could change the catchment EWR by altering the structure of the ecosystem.

\section{(2) Eco-water Deficit (EWD)}

Eco-water deficit (EWD) is simply defined as the difference between EWR and EWU in the catchment of interest, namely:

$E W D=E W R-E W U$

For a stable ecosystem, the catchment EWR varies within a certain range. However, the catchment EWU may change dramatically due to varying natural or human influences. Even when human interruption is absent, the instantaneous EWU does not always match the instantaneous EWR at any given time. But over the long-term, the mean EWU should be almost the same as the mean EWR, and EWD should be negligible. Therefore, EWD can be attributed mainly to human activities. EWD may be classified into two classes according to the means by which people deplete the EWU. The first class is named apparent EWD, which is caused by the reduction of the water available to natural ecosystems. For example, deforestation transfers water from the natural ecosystem to agriculture. Apparent EWD inevitably reduces the ecological services and functions that are available to human society. The second class, named latent EWD, is usually caused by the latent occupancy of EWU, without reduction of natural ecosystems. For example, groundwater over-exploitation causes 
the water table to fall, which eventually lowers the EWU of the ecosystem. Whereas it is relatively easy to determine the apparent EWD by monitoring the spatial pattern of natural ecosystems, it is more difficult to identify latent EWD, since the degradation of an ecosystem experiencing EWD takes time to occur.

\section{(3) Idea of Rapid Assessment of EWD}

Rapid assessment of EWD adopts the idea contained in RBA methods which were established in the 1980s for water quality assessment, with the structure of aquatic organism community used as an indicator. RBA methods are aimed to overcome the shortcomings of traditional physical and chemical methods, which are time-consuming, laborious, inefficient for large regions, and do not relate directly to the health of aquatic organisms. Typical RBA methods includethe River Invertebrate Prediction and Classification System (RIVPACS) (Wright et al., 1998), the Australian River Assessment System (AUSRIVAS) (Davies, 2000), and Rapid Bio-assessment Protocols (Barbour et al., 1999). The fact that RBA methods are essentially statistical models for single-factor assessments makes them more versatile than other techniques. The concept behind RBA methods has been applied in many other fields besides water quality assessment, such as soil erosion assessment (Ni and $\mathrm{Li}, 2003$ ). The idea of RBA can also be extended to rapid assessment of EWD. Specifically, EWD rapid assessment method presumes that EWR of ecosystems with similar environments should resemble each other. Sites with minimal human interference are selected as reference sites, and EWR characteristics and their environmental data are collected. These reference sites can be classified into several groups according to characteristics of EWR. Each test site is then classified into a reference group, using multiple discriminant analysis to determinethe test site's similarity to each reference group in terms of environmental (e.g. meteorological, topographical, hydrological) variables. Then, the predicted EWR characteristic is obtained for each test site. The discrepancy between the observed and predicted EWR characteristics is used to calculate an indicator related to the relative degree of severity of EWD for each test site. Finally the EWD indicator is used to evaluate EWD and further to identify the areas with most serious eco-water deficit.

\section{(4) Degree of Severity of EWD}

A measure of the degree of severity of EWD would be useful for determining whether the ecosystem can cope with human demand, and whether the natural ecosystem is short of water. In practice, it is difficult to establish an 'absolute' standard for the degree of severity of EWD for the following reasons. First, it is difficult to quantify the ecological services; second, human requirements for ecological services and environmental functions vary considerably; and finally, ecosystem deterioration is not exclusively caused by water shortage. A useful and convenient alternative is to establish a 'relative' indicator for the severity degree of EWD. Given that the EWD is the opposite of EWR for a given test catchment, its
EWD may therefore be evaluated by comparing the actual EWU to the values predicted by the reference catchments.

\subsection{Indicator for EWD Assessment}

Theoretically, EWU should be the best indicator for EWD assessment. By comparing the expected EWU, predicted using reference catchments, with the observed EWU for a given test catchment, both its apparent and latent EWD should be readily obtained. In practice, however, it is difficult to measure EWU because of its variability, which makes it necessary to use an alternative indicator. Since EWR is an intrinsic attribute of an ecosystem and relatively stable, it is reasonable to assess EWD in terms of EWR. Two steps are needed, as follows: (1) Assuming that the present EWR has been satisfied, i.e., the EWU is close to the EWR, the apparent EWD can be estimated by comparing the present EWR of the test site with that of the reference catchments, (2) Latent EWD leads to ecosystem degradation after a certain period of time. Since the EWR of the degraded ecosystem is generally less than that of the original one, the latent EWD can be estimated if time series data are available. However, the calculation of EWR also poses difficulty as it requires a lot of data. If we are interested in the 'relative' severity of EWD instead of the 'absolute' value of EWR, we can construct a 'relative indicator' to reflect the relative magnitude of catchment EWR. For an ecosystem, its EWR is mainly determined by its type and area. Therefore, the overall EWR for a catchment should be determined according to the catchment structure of sub-ecosystems, i.e. the types, areas and spatial pattern of the subecosystems, which to a large extent could be indirectly reflected by land use pattern (Figure 1). This fact makes it feasible to construct a 'relative indicator' for catchment EWR in terms of land use structure. The type of sub-ecosystem could be indicated by a weight reflecting its importance to catch-

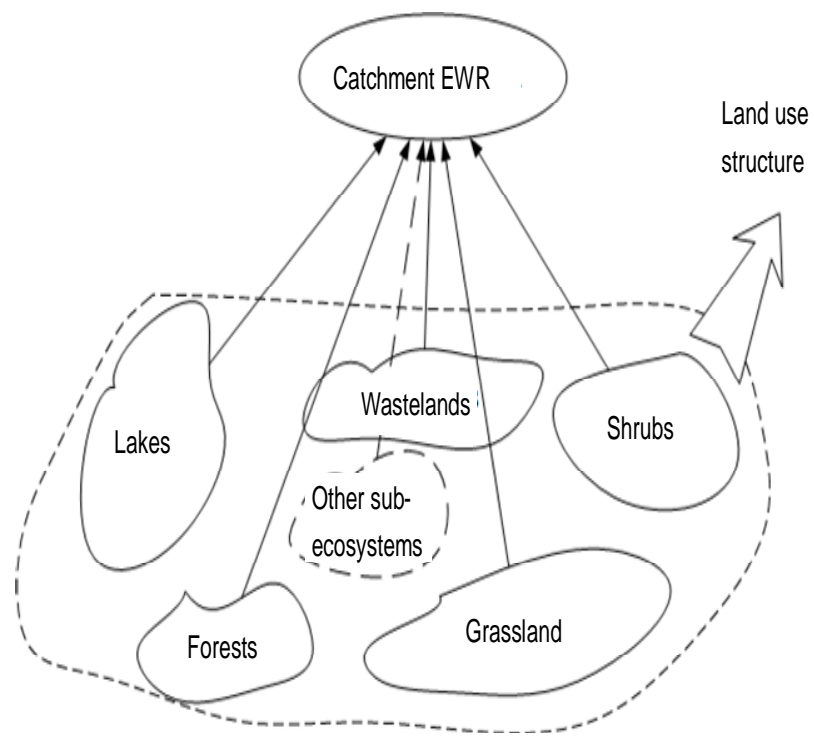

Figure 1. Relationship between catchment EWR and land use structure. 
ment EWR, and its area could be computed with land use data.

Thus, the indicator for catchment EWR (denoted EWRI) can be constructed in terms of land use structure, as shown by Equation (2):

$$
E W R I=\sum w_{i} \cdot A_{i} / A
$$

where $w_{i}$ is the weight of the $i^{\text {th }}$ sub-ecosystem, reflecting its significance to the catchment EWR; $A_{i}$ is the area of the $i^{\text {th }}$ ecosystem; and $A$ is the total area of the catchment. The value of $w_{i}$ is determined using the analytic hierarchy process (AHP) approach (Saaty, 1986). EWRI represents the relative amount of a catchment EWR. For a test catchment, by comparing its expected EWRI (denoted as EWRI $\mathrm{E}_{\mathrm{e}}$ ) predicted by reference catchments with its observed EWRI (denoted as EWRIo), the degree to which EWR is satisfied may be assessed; this is negatively related to the degree of severity of EWD.

\subsection{Assessment Procedure}

As noted previously, the EWR for a given catchment is determined by the structure of the sub-ecosystems, which is indirectly related to land use pattern (Figure 1). Climatic, edaphic, terrain, and human activity factors also influence the EWR. Therefore, EWRI, constructed according to the land use structure of a catchment, can reflect the relative magnitude of the catchment EWR. Climatic, edaphic and terrain factors are important environmental variables, which can be incorporated in the calculation of the test catchment EWRI. Figure 2 illustrates the entire assessment procedure, and the main steps are explained as follows.

\section{(1) Division of the Study Area and Integration of the Data}

It is necessary first to divide the catchment into a number of units, and then to integrate the data (such as climatic, edaphic and terrain factors, and landuse) for each unit. The division of the study area and integration of the data are undertaken using GIS tools like ArcGIS.

\section{(2) Selection of Reference Units to Construct Reference Groups}

Reference units provide a gauge by which the degree of severity of EWD is assessed for each test unit. In the present approach, two criteria are used for selecting reference units: one is that the units should have as little human impact as possible; and the other is that the units should be representative (that means they should have certain sample size and contain as many kinds of environmental conditions as possible within the whole catchment). The reference units are not necessarily located in the catchment under consideration. In cases where the entire catchment of interest is affected by human activities, it is impossible to select reference units located within the catchment, and the selection has to be performed from outside areas close to the catchment of interest.
Next, the reference units are clustered into several groups via a clustering analysis with regard to land use structure. The EWRI of each reference group is calculated as the mean EWRI value of its constituent members.

\section{(3) Selection of Environmental Variables}

Environmental variables are used to judge the similarity of the test unit to each reference group, so that the expected EWRI of the test unit can be estimated. Therefore, the selected environmental variables should highlight the differences between the reference groups. Hence, evenly distributed variables should not be selected as they contribute little to the variation of the reference groups. For instance, if precipitation is evenly distributed in a catchment, it should not be selected as environmental variable in this method. Moreover, they should not be significantly affected by human influences, since the assessment is a single-factor one for human impacts. Other key points in the selection procedure include: (a) the selected environmental variables should be as comprehensive as possible; (b) availability of the key data; (c) correlation between different factors enables factors with sufficient data to replace related ones without sufficient data; and (d) factors should be generalized or specified according to spatial scale. The selected environmental variables should be checked by discriminant analysis for the reference groups, and insignificant variables neglected. Discriminant analysis may also produce a new classification for the reference units, which can be compared against that from clustering analysis. Matching of the two classification results would indicate whether the environmental variables could explain most of the differences among the reference groups, and whether the environmental variables have been properly chosen. However, high correlation values may occur if many variables are involved, which makes a direct discriminant analysis infeasible. In that case, a principal component analysis (PCA) should be carried out, before the discriminant analysis.

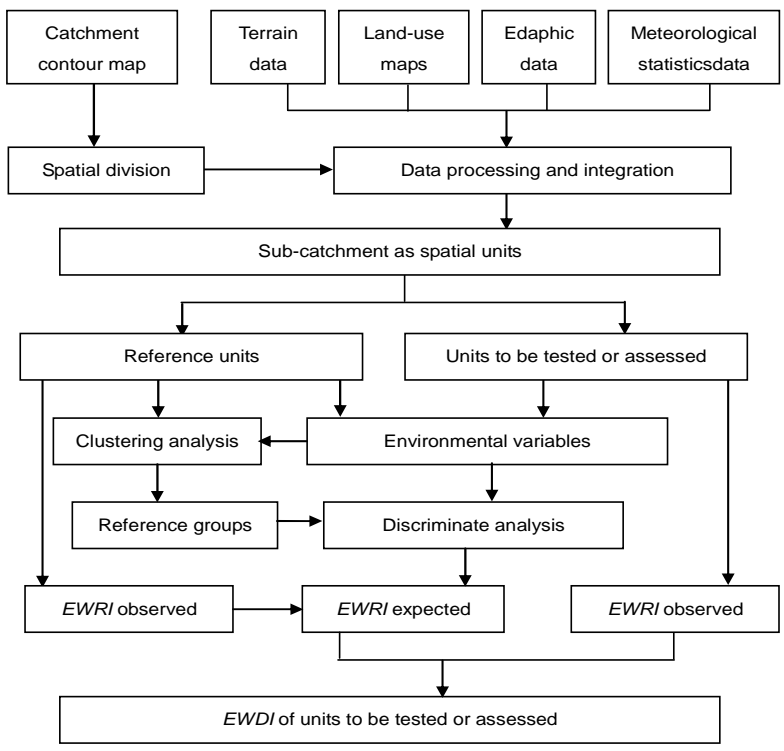

Figure 2. Flow chart of the rapid assessment method for catchment EWD assessment. 


\section{(4) Calculation of EWRIe}

Discriminant analysis is used to provide an estimate of the degree to which a particular test unit should be a member of a given reference group. The expected EWRI of the test unit $\left(\mathrm{EWRI}_{\mathrm{e}}\right)$ is calculated from:

$$
E W R I_{\mathrm{e}}=\sum p_{i} \cdot E W R I_{\mathrm{ri}}
$$

where $p_{i}$ is the membership degree of the test unit to the $i^{\text {th }}$ reference group; and EWRI $I_{\mathrm{ri}}$ is the EWRI of the $i^{\text {th }}$ reference group.

\section{(5) EWD Assessment for the Test Unit}

In this assessment, EWRI $\mathrm{E}_{\mathrm{e}}$ and $\mathrm{EWRI}_{\mathrm{o}}$ are substitutions for EWR and EWU, respectively. Therefore, an indicator for EWD (denoted as EWDI) can be constructed, as follows:

$$
E W D I=\left(E W R I_{\mathrm{e}}-E W R I_{\mathrm{o}}\right) / E W R I_{\mathrm{e}}=1-E W R I_{\mathrm{o}} / E W R I_{\mathrm{e}}
$$

Using EWDI, the relative severity of EWD of a test unit is determined. EWDI $<0$ indicates a positive effect on the ecosystem from human activities, whereas EWDI $>0$ indicates a negative impact. Once evaluated, EWDI is graded and the results may be plotted on a zonation map. In general, the EWDI values obtained for the reference units vary due to differences between the sub-ecosystems or due to fluctuations in the values held by the reference units themselves. This variation is an inherent property of a healthy ecosystem, and so the EWDI values of the test units are graded according to the scale of variation of EWDI of the reference units. Table 1 shows how the gradation is performed, assuming the range of the EWDI values of the reference units is $2 \sigma$, where $\sigma$ is the standard deviation of EWDI. The units with a Grade 4 EWDI can be identified as critical areas which should receive the highest priority in water management.

\section{EWR Deficit Assessment in the Yanhe River Catchment}

\subsection{Study Area and Data Processing}

(1) Study Area

The Yanhe River is one of the primary tributaries of the middle Yellow River, and is located in the north of Shaanxi Province, China (Figure 3). Its catchment ranges from $36^{\circ} 23^{\prime}$ to $37^{\circ} 17^{\prime} \mathrm{N}$ and $108^{\circ} 45^{\prime}$ to $110^{\circ} 28^{\prime} \mathrm{E}$, with a drainage area of $7,689 \mathrm{~km}^{2}$. The length of the main drainage path is $287 \mathrm{~km}$. The catchment covers several administrative districts of Yan'an City, including Baota District, Ansai County, Yanchang County, Zhidan County and Jingbian County. In 1996, the po-

Table 1. Grading Criteria for Degree of Severity of EWD Based on EWDI

\begin{tabular}{lll}
\hline Grade & Criterion & Description \\
\hline 0 & EWDI $<-\sigma$ & $\begin{array}{l}\text { Special class, where EWU of the test unit is larger than those of the reference units, } \\
\text { reflecting positive affect of human activities. }\end{array}$ \\
1 & $-\sigma \leq$ EWDI $\leq \sigma$ & EWU of the test unit is comparable to those of the reference units. \\
2 & $\sigma<$ EWDI $\leq 2 \sigma$ & EWU of the test unit has been slightly exploited. \\
3 & $2 \sigma<$ EWDI $\leq 3 \sigma$ & EWU of the test unit has been significantly exploited. \\
4 & EWDI $>3 \sigma$ & EWU of the test unit has been significantly exploited, and action is urgently required. \\
\hline${ }^{*} \sigma$ ' is the standard deviation of EWDI.
\end{tabular}
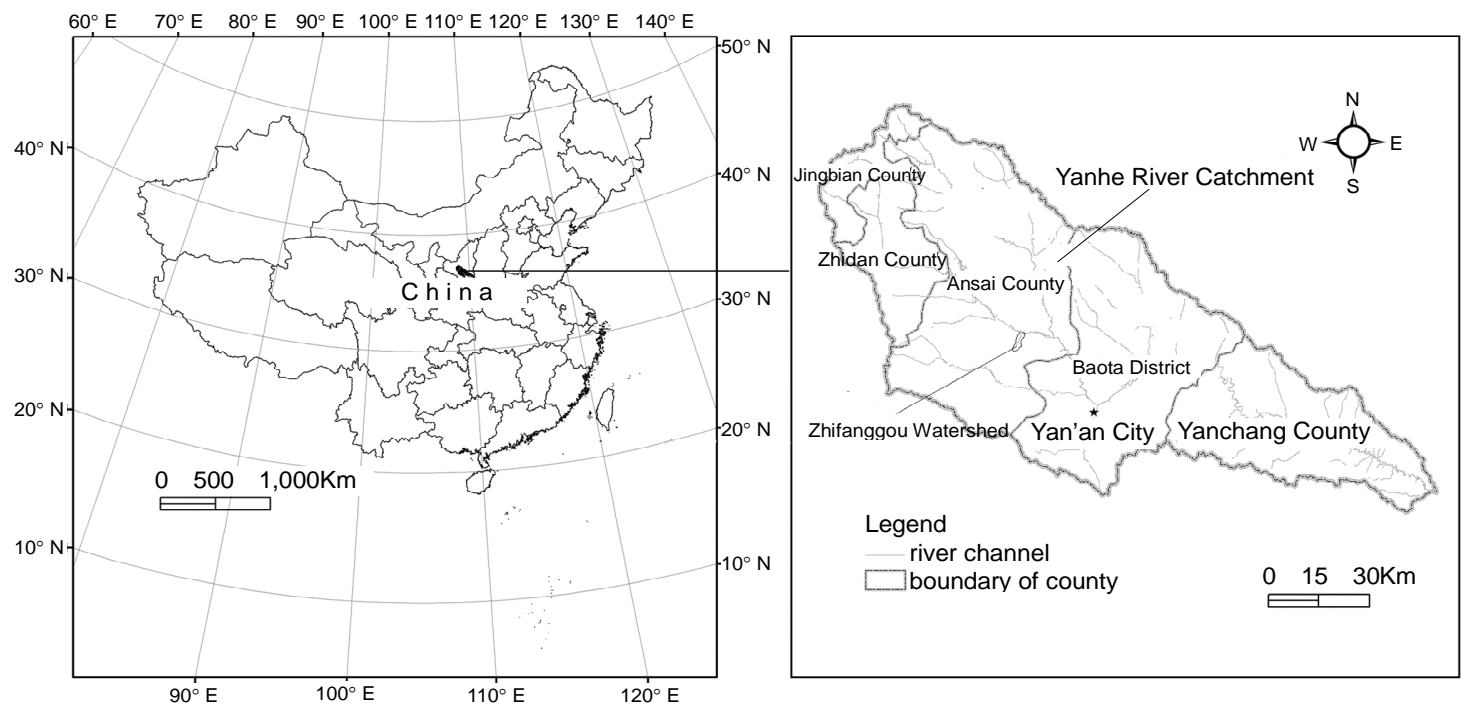

Figure 3. Location of the Yanhe River Catchment and the Zhifanggou Watershed. 
pulation of the Yanhe River basin was about 500,000 with a density of $65 / \mathrm{km}^{2}$; the GDP was 11.8 million RMB; the per capita food output was about $327 \mathrm{~kg}$; and $16 \%$ of the population were in poverty at that time.

The climate in this catchment is transitional between semihumid and semi-arid warm temperate zones. The temperature has a mean annual value between 8.8 and $10.2^{\circ} \mathrm{C}$, and ranges from -22.3 to $38.9{ }^{\circ} \mathrm{C}$. Sunlight occurs between 2,325 and 2,573 hours per year, and the frost-free season lasts for around 150 to 185 days. Mean annual precipitation is about $516 \mathrm{~mm}$, which is mostly summer rainfall (more than $60 \%$ of the total annual rainfall occurs between July and September). The mean annual runoff is $2.94 \times 10^{9} \mathrm{~m}^{3}$, with significant intrannual and inter-annual variability. The prevailing wind direction is northwest in winter and southeast in summer. The main soil types in this area include yellow brown soil, black loam soil, red soil and alluvial soil. Yellow brown soil predominates, having originated from the loess plateau, and is extremely vulnerable to soil erosion. Ravine erosion in the form of rills, shallow furrows and gullies is well developed in the catchment. The gully density is $4.7 \mathrm{~km} / \mathrm{km}^{2}$. The landscape is characterized by a rugged terrain with a gullied surface, whose altitude ranges from 504 to $1,731 \mathrm{~m}$. Soil erosion is severe with the mean annual value ranging from 9,000 to 15,000 $\mathrm{t} / \mathrm{km}^{2}$.

The Yanhe River has an average gradient of 0.0326 , and is located in a region where the vegetation transitions from forest to grass. Deciduous broadleaved forest crosses the northern boundary of the catchment, which has secondary forest in its southern part and forest-grass in its northern part. The dominant land use type is dry farmland.

\section{(2) Data Processing}

To apply the rapid assessment method, terrain, meteorological, edaphic, and land use data are needed. These data sets are relatively convenient to obtain than the data used for calculating absolute EWD. Terrain information was derived from a 1:50,000 scale contour map of the study area. First, the con- tour map was transferred into a digital elevation model (DEM). Next, the catchment was divided into 512 units, and the river network extracted using the hydrological module of ArcGIS 8.1. By interpreting the DEM, the following four terrain variables were computed for each unit: mean altitude; mean slope; relative difference in altitude; and gully density. Nine meteorological variables were selected, comprising the annual mean temperature, annual mean accumulated temperature from April to September, annual mean variation coefficient of temperature, annual mean precipitation, annual mean accumulated precipitation from April to September, annual variation coefficient of precipitation, annual mean hours of sunlight, annual mean accumulated hours of sunlight from April to September, and annual variation coefficient of hours of sunlight. The meteorological data were taken from stations within or near the Yanhe River catchment, the information extracted from a daily meteorological database of 192 stations from 1955 to 1990. With the help of ArcGIS, a raster map for each meteorological variable was first produced by kriging interpolation, and then the data for each variable integrated over each unit. The edaphic data were represented using a soil variable, based on the ratio of the area covered by yellow brown soil to the total area, which was calculated using ArcGIS. It should be noted that soil type was not selected as the variable as yellow brown soil is dominant throughout the catchment, and so soil type would be the same for most of the units and therefore not significant in the assessment.

Certain of the fourteen variables listed may be correlated, which is undesirable when carrying out discriminant analysis as part of the rapid assessment method. Thus, a principal component analysis (PCA) was performed to obtain four principal components from these fourteen variables (see Table 2). These four principal components served as the environmental variables for the following assessment.

\subsection{Method Application}

\section{(1) EWRI}

Table 2. Matrix from Principal Component Analysis

\begin{tabular}{lllll}
\hline \multirow{2}{*}{ Variables } & \multicolumn{4}{c}{ Principal Component } \\
\cline { 2 - 4 } & 1 & 2 & 3 & 4 \\
\hline Gully density & -0.188 & 0.136 & $-\mathbf{0 . 4 3 2}$ & -0.053 \\
Elevation & $\mathbf{- 0 . 7 3 1}$ & -0.470 & -0.327 & 0.248 \\
Slope & -0.176 & 0.018 & -0.046 & $\mathbf{0 . 9 6 3}$ \\
Relative difference in altitude & -0.101 & 0.057 & -0.053 & $\mathbf{0 . 9 6 0}$ \\
Percentage of yellow brown soil & -0.300 & -0.375 & -0.078 & $\mathbf{0 . 4 6 7}$ \\
Mean annual temperature & 0.355 & -0.253 & $\mathbf{0 . 8 5 1}$ & -0.178 \\
Cumulative temperature (Apr - Sep) & 0.199 & 0.312 & $\mathbf{0 . 9 0 9}$ & -0.091 \\
Variation coefficient of temperature & $\mathbf{- 0 . 9 5 7}$ & 0.236 & -0.059 & 0.149 \\
Mean annual precipitation & $\mathbf{0 . 9 0 8}$ & 0.058 & 0.380 & -0.156 \\
Precipitation (Apr - Sep) & $\mathbf{0 . 8 8 3}$ & 0.004 & 0.436 & -0.162 \\
Variation coefficient of precipitation & $\mathbf{0 . 8 4 8}$ & 0.138 & 0.480 & -0.155 \\
Mean annual hours of sunshine & 0.070 & $\mathbf{0 . 9 7 5}$ & -0.130 & 0.014 \\
Hours of sunshine (Apr - Sep) & 0.033 & $\mathbf{0 . 9 9 0}$ & -0.011 & 0.015 \\
Variation coefficient of hours of sunshine & $\mathbf{0 . 8 7 1}$ & 0.450 & 0.104 & -0.109 \\
\hline * Bold type indicates the highest score a variable has aross the range of principal components.
\end{tabular}

*Bold type indicates the highest score a variable has across the range of principal components. 
We considered seven types of ecosystems in the Yanhe River catchment: water body, forest, scrubland, grassland, wasteland, farmland, and urban. The area of each sub-ecosystem was calculated from the 1:50,000 land use map and their weights with regard to catchment EWR were determined by pairwise comparisons using the AHP approach (Table 3). Thus the observed indicator of EWR, EWRIo, was calculated for each unit.

Expert opinion was utilized in performing the pairwise comparisons to determine the relative importance of each pair of ecosystems. The water body ecosystem was assigned the largest weight mainly because water surface evaporation is significant, affecting other environmental functions such as maintaining the habitatfor aquaticorganisms, sediment transport, etc. This decision takes account of the findings by $\mathrm{Yu}$ and Chen (1996), who monitored water consumption by forest land, scrubland, grassland and wasteland in a loess area similar to the present study area for five years. Urban and farmland ecosystems received the lowest weights because these two ecosystems were strongly influenced by human activities. Taking account of the available information on the Yanhe River catchment sub-ecosystem characteristics, the ranking of the ecosystems based on their relative importance to the rapid assessment method is as follows in descending order: water body, forest land, scrubland, grassland, wasteland, farmland and urban.

\section{(2) Reference Units and Groups}

The principles in selecting the reference units as describbed above. The only land use data available to the study were from 1990 and 2000. In general, the magnitude of human impact increased with time. Therefore, the reference units were determined from the land use data in 1990, when there were certain areas that had not yet been disturbed by human activities (already extensive in much of the Yanhe River catchment). The ratio of urban and farmland area to the total area was calculated for each unit and the entire catchment. It was found that this area ratio approximates a normal distribution (the w-value by the Shapiro-Wilk method equals 0.9625 , close to 1 ) for the Yanhe River catchment. For a random variable subject to the normal distribution $\mathrm{N}\left(\mu, \sigma^{2}\right)$, the probability that its value falls outside the interval $[\mu-2 \sigma, \mu+$ $2 \sigma]$ is only $5 \%$; here, abnormal values are defined as observed values that are not within this interval. From the 1990 land use data, the area ratio of urban and farmland in the Yanhe River catchment has a mean of 0.401 , and a standard deviation of 0.096 . Thus, the interval used to screen abnormal values was [0.209, 0.592]. Since we are interested in low human impact, units with an area ratio less than 0.209 were selected as candidates to become reference units. The least affected 50 units were then selected as the reference units. The reference units were then classified into five reference groups, by a clustering analysis according to the degree of similarity of their land use structure. This was undertaken using the software package, SPSS. Table 4 lists percentage values of the mean land use structure and EWRI calculated for each reference group.

\section{(3) EWRI $_{e}$ and EWDI}

Using the data on the environmental variables, discriminant analysis was applied to calculate the membership degree (probability) of each test unit to each reference group. The EWRI $_{e}$ was calculated for each test unit by summing the products of its probability of membership of each reference group and the average EWRI of the corresponding reference group. Then, the EWDI was calculated for each test unit following the assessment procedure. Discriminant analysis was also used to classify the test units according to the reference groups. By treating the reference units as test units and adding them into the discriminant analysis, a new classification of the reference units was achieved. Comparison between the new classification and the original one (obtained by constructing

Table 3. Pairwise Comparison Matrix and Weights for Sub-ecosystems Subject to EWR in the Yanhe River Catchment

\begin{tabular}{lllllllll}
\hline & Water Body & Forest & Scrubland & Grassland & Wasteland & Farmland & Urban & Weight \\
\hline Water Body & 1 & 2 & 4 & 5 & 7 & 8 & 9 & 0.3860 \\
Forest & $1 / 2$ & 1 & 3 & 4 & 6 & 7 & 8 & 0.2747 \\
Scrubland & $1 / 4$ & $1 / 3$ & 1 & 2 & 4 & 5 & 6 & 0.1426 \\
Grassland & $1 / 5$ & $1 / 4$ & $1 / 2$ & 1 & 2 & 3 & 4 & 0.0843 \\
Wasteland & $1 / 7$ & $1 / 6$ & $1 / 4$ & $1 / 2$ & 1 & 2 & 3 & 0.0519 \\
Farmland & $1 / 8$ & $1 / 7$ & $1 / 5$ & $1 / 3$ & $1 / 2$ & 1 & 2 & 0.0352 \\
Urban & $1 / 9$ & $1 / 8$ & $1 / 6$ & $1 / 4$ & $1 / 3$ & $1 / 2$ & 1 & 0.0251 \\
\hline "Consistency ratio, $C R=0.0534<0.1$, and so the pairwise comparison matrix passed the verification test for consistency.
\end{tabular}

Table 4. Mean Land-use Structure (\%) and EWRI (\%) for Each Reference Group in the Yanhe River Catchment

\begin{tabular}{llllllllll}
\hline Group & No. of Units & Urban & Farmland & Water & Forest & Scrubland & Grassland & Wasteland & EWRI \\
\hline GP1 & 6 & 0.0 & 19.7 & 0.2 & 45.1 & 4.7 & 30.2 & 0.0 & 16.6 \\
GP2 & 4 & 0.4 & 18.9 & 0.1 & 1.9 & 37.9 & 40.8 & 0.0 & 10.5 \\
GP3 & 14 & 0.0 & 14.9 & 0.0 & 81.9 & 0.4 & 2.8 & 0.0 & 23.1 \\
GP4 & 25 & 0.1 & 23.7 & 1.2 & 5.9 & 1.5 & 67.5 & 0.0 & 9.7 \\
GP5 & 1 & 0.0 & 19.0 & 0.6 & 34.5 & 41.8 & 3.9 & 0.0 & 16.5 \\
\hline
\end{tabular}


Table 5. Grading Criteria for Degree of Severity of EWD Based on EWDI in the Yanhe River Catchment

\begin{tabular}{lll}
\hline Grade & Criterion & Description \\
\hline 0 & EWDI $<-0.11$ & $\begin{array}{l}\text { Special class, where EWU of the test unit is larger than those of the reference units, reflect- } \\
\text { ing positive affect of human activities }\end{array}$ \\
1 & $-0.11 \leq$ EWDI $\leq 0.11$ & EWU of the test unit is comparable to those of the reference units \\
2 & $0.11<$ EWDI $\leq 0.33$ & EWU of the test unit has been slightly exploited \\
3 & $0.33<$ EWDI $\leq 0.55$ & EWU of the test unit has been significantly exploited \\
4 & EWDI $>0.55$ & EWU of the test unit has been significantly exploited, and action is urgently required \\
\hline
\end{tabular}

reference groups using clustering analysis) was used to justify the selection of the environmental variables. Herein, $76 \%$ of the reference units were classified into the same groups by both analysis techniques, indicating that the selected environmental variables were consistently representing the majority of the differences among the reference groups. Table 5 lists the grading criteria used to evaluate the degree of severity of EWD based on the EWDI value for the Yanhe River catchment. It should be noted that the variance of EWDI of the reference units is approximately 0.22 .

\subsection{Assessment Results}

(1) EWDI Statistics and Spatial Distribution in 1990 and 2000

In the assessment undertaken for the 1990 scenario, units other than reference ones were treated as test units, and areas with apparent EWD were identified. In the assessment for the 2000 scenario, all units were treated as test units, and the results indicate the latent EWD in 1990 and the apparent EWD in 2000. Here, apparent EWD refers to EWD due to the decreasing area of the ecosystem because of human activities such as deforestation, and latent EWD refers to changes to water storage within the system. Areas with most severe EWD were again identified. Furthermore, comparison between the results obtained for the two scenarios provided insight into the dynamics of EWD. Table 6 shows the statistics of the different EWDI grades of 1990. There are 126 units in Grade 3 and 4 , accounting for about $26 \%$ of the total area of the catchment; and there are 38 units in Grade 4, accounting for about $10 \%$ of the total area. This indicates that certain sub-catchments of the Yanhe River Catchment were suffering very severe EWD in 1990. These units distribute in the southwest of the catchment (Figure 4), mainly in the Baota District and south Ansai County.

The assessment results for Year 2000 is shown in Figure 5 and the statistics of EWDI grades is presented in Table 7. Form Table 7, there are 169 units in Grade 3 and 4, accounting for about $37.5 \%$ of the total area of the catchment; and there are 58 units in Grade 4, accounting for about 14.9\% of the total area. This indicates that more sub-catchments were suffering very severe EWD in 2000 than in 1990. The units suffering very severe EWD mainly distribute in southern west corner of the catchment. It also can be found that several units sparsely distribute in the north part of basin along to the boundary. The average values of EWDI in 1990 and 2000 are 0.25 and 0.31 respectively, which indicates that EWD in the Yanhe River catchment experienced an exacerbating trend from
Table 6. Statistics of EWDI Grades for the Yanhe River Catchment in 1990

\begin{tabular}{llll}
\hline Grade of EWDI & No. of Units & Area $\left(\mathrm{km}^{2}\right)$ & Area Ratio $(\%)$ \\
\hline 0 & 17 & 418.9 & 5.5 \\
1 & 62 & 936.0 & 12.2 \\
2 & 307 & 4286.7 & 56.0 \\
3 & 88 & 1203.5 & 15.7 \\
4 & 38 & 807.2 & 10.6 \\
Total & 512 & 7652.3 & 100 \\
\hline
\end{tabular}

1990 to 2000 in general. On the other hand, since the units (sub-catchments) suffering little human disturbance were used as reference in the both assessment, the increase of EWDI also suggested that human interference had been intensified in this 10 year period.

\section{(2) Critical Units and their Spatial Distribution in 2000}

For water resource management purposes, it is obvious that any units with Grade 4 EWDI or which have experienced a significant increase in EWDI over time (considering the 1990 and 2000 results) should be subject to further investigation. Given the variance (see Table 5) of EWDI grades of the reference units is 0.22 , any units where EWDI increased by

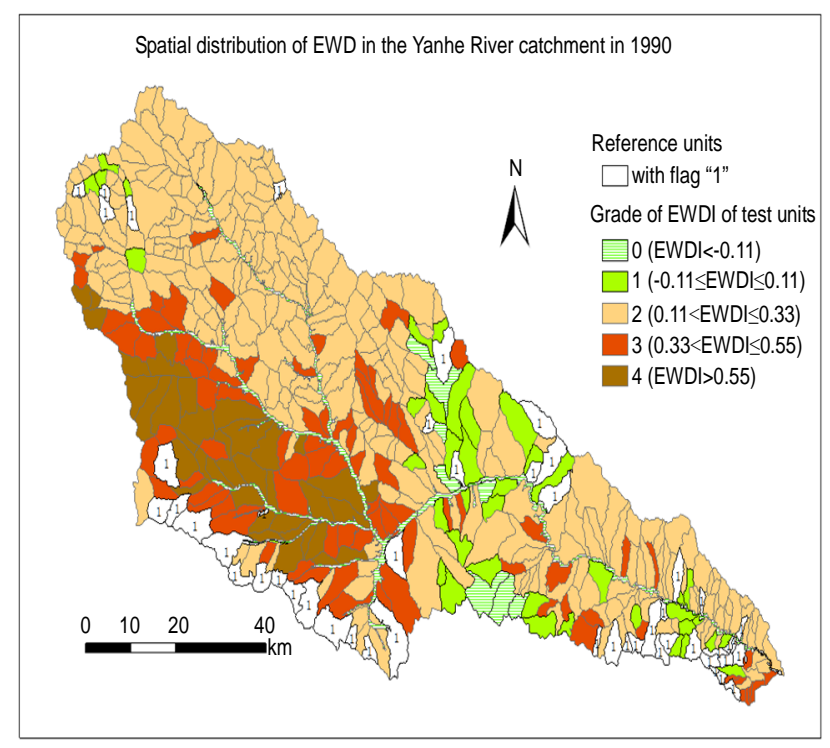

Figure 4. Spatial distribution of EWD in the Yanhe River catchment in 1990 . 
Table 7. Statistics of EWDI Grades for the Yanhe River Catchment in 2000

\begin{tabular}{llll}
\hline Grade of EWDI & No. of Units & Area $\left(\mathrm{km}^{2}\right)$ & Area Ratio (\%) \\
\hline 0 & 18 & 330.2 & 4.3 \\
1 & 43 & 504.0 & 6.6 \\
2 & 282 & 3951.7 & 51.6 \\
3 & 111 & 1724.5 & 22.6 \\
4 & 58 & 1142.1 & 14.9 \\
Total & 512 & 7652.4 & 100.0 \\
\hline
\end{tabular}

more than 0.22 from 1990 to 2000 will be classified into the higher grade of EWD, thus those units were deemed to have suffered significant degradation regarding EWD. The areas containing such units were identified as critical units as displayed in Figure 6. As Figure 6 shows, the areas with severe EWD mainly distribute in south Ansai County and the majority of Baota District. Another important finding is that the majority of small catchments around Yan'an City had Grade 4 EWDI, and some of them also experienced a significant increase in EWDI from 1990 to 2000. To address the water resources re-allocation and ecological reconstruction issues, priority attention should be paid on these areas. In addition, further investigation can be carried out on these sub-catchments by the proposed method if more detailed data is available, its results will be helpful to formulate a pertinent water resource allocation scheme or to implement appropriate ecological protection measures.

\section{Discussion}

\subsection{Rationality of the Assessment}

Because EWU varies greatly, and observed data on EWU are hard to obtain, most related studies in the literature present results without systematic validation, and base their discussions on non-validated results (Zhao et al., 2007). A few studies (such as that of $\mathrm{Ni}$ et al., 2002) attempt validation by comparing their results against those of other studies, but not observed data. In the present work, it is possible to consider validation using observed hydrologic data and other relevant studies.

The long-time (1952-2008) average annual precipitation in the Yanhe River catchment is $506.71 \mathrm{~mm}$, and average values of annual precipitation in the period of 1981-1990 and 1991-2000 are 530.40 and $448.40 \mathrm{~mm}$ respectively (Ren et al., 2012). The average runoff in the two periods observed at Ganguyi hydrological station which controls the $76.3 \%$ area of the Yanhe River catchment, did not change too much $\left(2.16 \times 10^{8}\right.$ vs $1.94 \times 10^{8} \mathrm{~m}^{3}$ ), this verified that the EWD in the catchment is worsened from 1990 to 2000 . The present assessment showed that average EWDI in 1990 and 2000 are 0.25 and 0.31 respectively which suggests that the catchment experienced an exacerbated trend of EWD. The result can also match the findings of Qiu et al. (2011) that it is drier in 2000 than in the other years within the past two decades.

Another validation of the assessment can resort to the results in the Zhifanggou watershed which covers an area of
$8.27 \mathrm{~km}^{2}$ and is one of the 512 units in the Yanhe River catchment (Figure 3). Though the catchment was classified as Grade 2 in 1990 and 2000 according to EWDI, the absolute values of EWDI are 0.25 and 0.21 in 1990 and 2000 respectively, which indicates that the EWD was improved in the period. The present results are in agreement with the actual situation and also closely match the findings of Liu et al. (2003) who assessed the health of the eco-economy system of the Zhifanggou watershed using an ecosystem health index over the period from 1985 to 1999 , and those of Wen et al. (2004) who analyzed the impact of landscape change on the environment of the watershed, based on 60-year land use data.

It should be noted that because the present method requ-

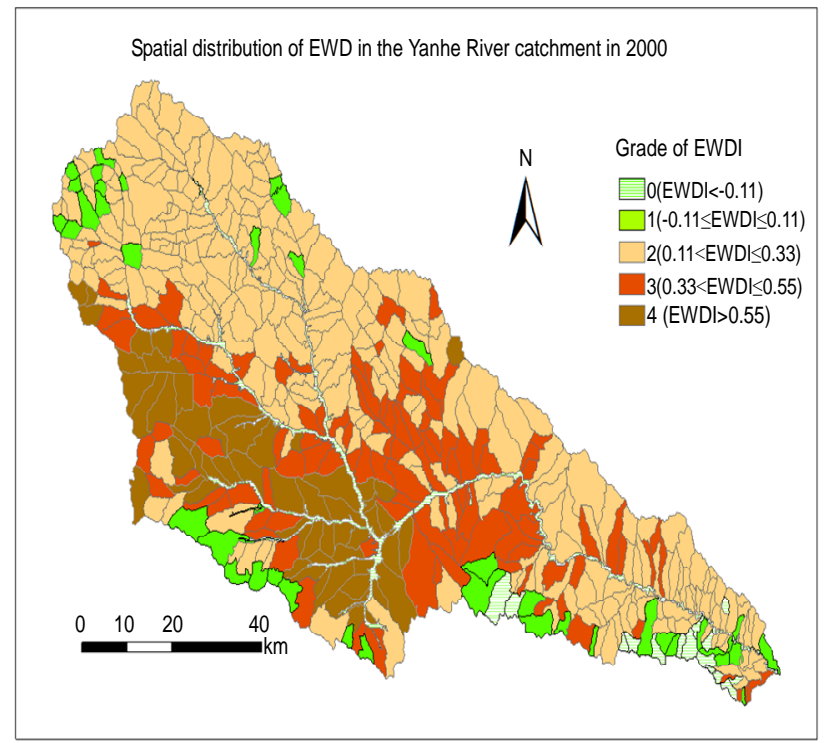

Figure 5. Spatial distribution of each grade of cells in Yanhe catchment in 2000 .

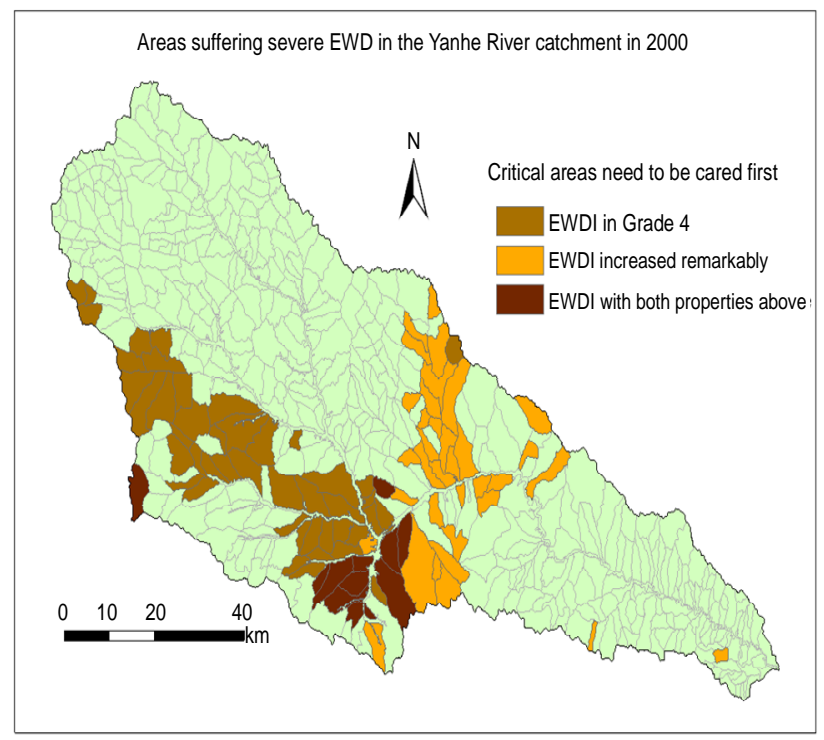

Figure 6. Areas suffering severe EWD in the Yanhe River catchment in 2000 . 
ires the reference units to be almost unaffected by human impact, the standard of EWD constructed in this way may be too strict. Therefore, the grading reveals the degree of severity of EWD in a relativesense rather than an absolute sense. Although certain units have high grades based on the indicator of eco-water deficit EWDI, this does not necessarily mean that they are actually experiencing severe EWD in an absolute sense. However, those units that have a high grade classification should still be considered ahead of other units with low grades, as far as management issues associated with EWR are concerned.

\subsection{Method Flexibility}

In the case study, the units unaffected by human impact are taken as reference units and then the critical areas are identified. If time series of land use data are available, the present approach can be used to monitor the dynamics of EWD for a given catchment. In this case, reference units chosen from the earliest period can be used as a benchmark and EWD assessed for each period in a similar way to that based on a single period of land use map. The areas where the EWDI value has increased significantly should be further investigated, as this may indicate over-exploitation of the EWU. By tracing the dynamics of EWD for a catchment, it is possible to monitor the temporal effect of EWU reallocation, providing useful information for decision makers involved in water management and ecosystem reconstruction.

In the case study, the river catchment is used as assessing unit. A catchment is a stratified system, it can be divided into multiple sub-catchments, each of which could be further divided recursively into smaller units until a desired scale is reached. The method can be applied conveniently to catchments of different spatial scale. The EWD of a particular catchment may be quite different from that of its constituent sub-catchments. For example, a catchment may suffer severe EWD while several of its sub-catchments may have low EWD. Therefore, in order to distinguish appropriately those areas with most severe EWD and in order to meet water management requirements, assessment of the catchment EWD should be performed top down through the stratified structure if data available.

In the case study, sub-catchment is used as the spatial unit for data integration and model calculation. In fact, as a GIS-supported data integration and modeling, the proposed method can also adopt some other analysis units such as integrated information unit (Ni et al., 2003), minimum unit (Li et al., 2003), minimum polygons (Ni et al., 2008) and smart coded polygon (Ni et al., 2014) successfully used in data organization and model integration to assess EWD in a given catchment. In that case, because these kinds of analysis units can not represent the intrinsic nature of stratified structure of catchments, they cannot be used to identify areas suffering severe EWD, grade by grade from top to bottom of the stratified structure of the catchment.

\section{Conclusions}

This paper has presented a rapid assessment method for EWD in a catchment system, which could be employed to identify areas with severe EWD that are of the highest priority with regard to eco-water allocation. The model framework involves concepts of EWR and EWD, environmental factors that influence EWR, and a relative indicator EWRI which can be defined as the sum of products between the weight representing the level of importance of each sub-ecosystem to EWR in a given ecosystem (catchment) and its area percentage over the total area. The weights can be determined by analytic hierarchy process (AHP), and the area of sub-ecosystems could be computed with land use maps. The proposed method evaluates EWRI based on land use data through the following procedure: 1) dividing the study area into spatial elements termed units; 2) selecting reference units by which to establish reference groups; 3) matching the test unit to the reference groups to calculate its expected EWRI; 4) comparing the expected and the observed EWRIs to calculate EWDI by subtracting the ratio of observed and expected EWRI from 1; and 5) finally identifying areas with most serious eco-water deficit in terms of EWDI. A case of eco-water deficit assessment has conducted in the Yanhe River catchment, in northwest China. The assessment indicates that areas with most severe ecowater deficit are located in south Ansai County, regions around Yan'an City, and Baota District. It was found that the method gave sensible results, and, in principle, could be used to identify areas suffering severe EWD.

In this method, EWRI is defined to repent the EWR, which can bypass the difficulties in absolute EWR estimation. Main data sets required by this proposed method are hydrological data, meteorological data and land use maps which are more convenient to obtain than data required for calculating absolute EWR and EWU. The method can be used to evaluate the effect of practical eco-water use and assist decision making with regard to eco-water reallocation, provided time series data are available on landuse. Sub-catchments are used as the units for assessment, which facilitate the application of the rapid assessment method at various spatial scales. By incorporating standard statistical methods in the model framework, the method is easy to use and can rapidly reveal the severity of EWD for a catchment of large area. The present method can also be applied to reveal dynamic changes to the catchment EWD if time series data are available, and hence provide useful information for adaptive water resources management.

Since the method can only provide relative degree of E$\mathrm{WD}$, future work is recommended in order to improve the method so that the relative EWDI can be readily calibrated to give an absolute indicator such as amount of water deficit. This would require alternative information on the health of the sub-ecosystems and of course be catchment specific.

Acknowledgments. This work was supported by the National Natural Science Foundation of China with Grant No. 51379010 and the National Basic Research Program of China with Grant No. 2007CB 407202. Support from Collaborative Innovation Center for Regional Environmental Quality is also acknowledged. 


\section{References}

Acreman, M.C. and Ferguson, A.J.D. (2010). Environmental flows and the European Water Framework Directive. Freshw. Biol., 55(1), 32-48. http://dx.doi.org/0.1111/j.1365-2427.2009. 02181.x

Barbour, M.T., Gerritsen, J., Snyder, B.D., and Stribling, J.B. (1999). Rapid Bioassessment Protocols for Use in Streams and Wadeable Rivers: Periphyton, Benthic Macroinvertebrates, and Fish (Second edition), United States Environmental Prote- ction Agency, Office of Wate, Washington, D.C., EPA 841-B-99-002. http://hdl.handle. net/1969.3/27927

Cai, Y.P., Huang, G.H., Yang, Z.F., Lin, Q.G., and Tan, Q. (2009a). Community-scale renewable energy systems planning under uncertainty - An interval chance-constrained programming approach Renew. Sust. Energ. Rev., 13(4), 721-735. https://doi.org/10.1016/j. rser.2008.01.008

Cai, Y.P., Huang, G.H., Yang, Z.F., and Tan, Q. (2009b). Identification of optimal strategies for energy management systems planning under multiple uncertainties, Applied Energy, 86(4), 480-495. https://doi.org/10.1016/j.apenergy.2008.09.025

Chen, X.J., Huang, G.H., An, C.J., Yao, Y., and Zhao, S. (2018). Emerging $\mathrm{N}$-nitrosamines and $\mathrm{N}$-nitramines from amine-based postcombustion $\mathrm{CO} 2$ capture - A review. Chem. Eng. J., 335, 921-935. https://doi.org/10.1016/j.cej.2017.11.032

Costanza, R., d'Arge, R., de Groot, R., Farber, S., Grasso, M., Hannon, B., Limburg, K., Naeem, S., ONeill, R.V., Paruelo, J., Raskin, R.G., Sutton, P., and vandenBelt, M. (1997). The value of the world's ecosystem services and natural capital. Nature, 387(6630), 253-260. http://dx.doi.org/10.1038/387253 a0

Cui, B., Tang, N., Zhao, X., and Bai, J. (2009). A management-oriented valuation method to determine ecological water requirement for wetlands in the Yellow River Delta of China. J. Nat. Conserv. 17(3), 129-141. http://dx.doi.org/10.1016/j.jnc.2009.01. 003

Davies, P.E. (2000). Development of a national bioassessment system (AUSRIVAS) in Australia. In: Wright J. F., Sutcliffe D. W., Furse M. T., (eds.), Assessing the Biological Quality of Freshwaters: RIVPACS and Other Techniques. Freshwater Biological Association, Ambleside, pp. 113-124.

Deutsch, L., Folke, C., and Skanberg, K. (2003). The critical natural capital of ecosystem performance as insurance for human welleing. Ecol. Econ., 44(2-3), 205-217. http://dx.doi.org/10.1016/s0 921-8009(02)00274-4

Falkenmark, M., and Rockstrom, J. (2004). Balancing Water for Humans and Nature: The New Approach in Ecohydrology, Earthscan Publications, London.

Fan, Y.R. and Huang, G.H. (2012) A robust two-step method for solving interval linear programming problems within an environmental management context, J. Environ. Inf., 19(1), 1-9. http://dx. doi.org/10.3808/jei.201200203

Gippel, G.J., and Stewardson, M.J. (1998). Use of wetted perimeter in defining minimum environmental flows. Regul. Rivers: Res. Manage., 14(1), 53-67. http://dx.doi.org/10.1002/(SICI)1099-1646 $(199801 / 02) 14: 1<53:: A I D-R R R 476>3.3 . C O ; 2-Q$.

Huang, G.H., and Cao, M.F. (2011). Analysis of solution methods for interval linear programming. J. Environ. Inf., 17(2), 54-64. http:// dx.doi.org/10.3808/jei.201100187

Hughes, D.A., Hannart, P., and Watkins, D. (2003). Continuous baseflow separation from time series of daily and monthly streamflow data. Water Sa, 29(1), 43-48. http://dx.doi.org/10.4314/wsa.v29i1. 4945

Jia, Z.H. and Luo, W. (2006). Modeling net water requirements for wetlands in semi-arid regions. Agric. Water Manage., 81(3), 282294. http://dx.doi.org/10.1016/j.agwat.2005.04.012

Jowett, I.G. (1997). Instream flow methods: a comparison of ap- proaches. Regul. Rivers: Res. Manage., 13(2), 115-127. http://dx. doi.org/10.1002/(SICI)1099-1646(199703)13:2<115::AID-RRR44 $0>3.0 . \mathrm{CO} ; 2-6$

King, J.M. and Louw, D. (1998). Instream flow assessments for regulated rivers in South Africa using the Building Block Methodology. Aquat. Ecosyst. Health Manage., 1(2), 109-124. http://dx. doi.org/10.1016/S1463-4988(98)00018-9

Liu, C.M. (1999). Supply demand analysis of water resources in 21st century in China: Study on ecological water conservancy. China Water Resour., (10), 18-20. (in Chinese)

Li, Y.P., Huang, G.H., Huang, Y.F., and Zhou, H.D. (2009). A multistage fuzzy-stochastic programming model for supporting sustainable water-resources allocation and management. Environ. Model. Software, 24(7), 786-797. https://doi.org/10.1016/j.envsoft. 2008.11.008

Li, Y.P., and Huang, G.H. (2009). Fuzzy-stochastic-based violation analysis method for planning water resources management systems with uncertain information. Inf. Sci., 179(24), 4261-4276. https://doi.org/10.1016/j.ins.2009.09.001

Li, T.H., Sun, Y.X., and Xue, A. (2003). Integration of fertilizing models with GIS using minimum units. Environ. Model. Software, 18(3), 221-229. http://dx.doi.org/10.1016/S1364-8152(02)00093-2

Liu, G.B., Hu, W.Y., and Xu, M.X. (2003). An analysis on ecoeconomy system health in Zhifangou small watershed of Ansai in the Loess hilly-gullied region. J. Nat. Resour., 18(1), 44-49. (in Chinese)

Luo, H.M., Li, T.H., Ni, J.R., and Wang, Y.D. (2004). Water demand for ecosystem protection in rivers with hyper-concentrated sediment-laden flow. Sci. China Ser: Eng. Mater. Sci., 47(1S), 186198. http://dx.doi.org/10.1360/04ez0016

Mosely, M.P. (1982). Analysis of the effect of changing discharge on channel morphology and instream uses in a braided river, Ohau River, New Zealand. Water Resou. Res., 18(4), 800-812. http://dx. doi.org/10.1029/WR018i004p00800

Ni, J.R., Jin, L., Zhao, Y.A., and Liu, X.Y. (2002). Minimum water demand for ecosystem protection in the Lower Yellow River. $J$. Hydraul. Eng., (10), 1-7. (in Chinese)

Ni, J.R., Li, X.X., and Borthwick, A.G.L. (2008). Soil erosion assessment based on minimum polygons in the Yellow River basin, China. Geomorphology, 93(3-4), 233-252. http://dx.doi.org/10.10 16/j.geomorph.2007.02.015

Ni, J.R., and Li, Y.K. (2003). Approach to soil erosion assessment in terms of land-use structure changes. J. Soil Water Conserv., 58(3), 158-169.

Ni, J.R., Wu, A., Li,T.H., Yue, Y., and Borthwick, A.G.L.(2014). Efficient soil loss assessment for large basins using smart coded polygons. J. Environ. Inf., 23(2), 47-57. http://dx.doi.org/10.3808/ jei.201400264

Pastor, A.V., Ludwig, F., Biemans, H., Hoff, H., and Kabat, P. (2014). Accounting for environmental flow requirements in global water assessments. Hydrol. Earth Syst. Sci., 18(12), 5041-5059. http://dx. doi.org/10.5194/hess-18-5041-2014

Qiu, L.L., Zheng, F.L., Yin, R.S., and Yu, F.Y. (2011). Quantification of impacts of precipitation change and human activities on streamflow in the Yanhe River basin. Adv. Clim. Change Res., 7(5), 357362. (in Chinese)

Ren, Z.P., Zhang, G.H., and Yang, Q.K. (2012). Characteristics of runoff and sediment variation in Yanhe River Basin in last 50 years. J. China Hydrol., 32(5), 81-86. (in Chinese)

Richter, B.D., Baumgartner, J.V., Wigington, R., and Braun, D.P. (1997). How much water does a river need? Freshw. Biol., 37(1), 231-249. http://dx.doi.org/10.1046/j.1365-2427.1997.00 153.x

Saaty, T.L. (1986). Axiomatic Foundation of the Analytic Hierarchy Process. Manage. Sci., 32(7), 841-855. http://dx.doi.org/10.1287/ 
mnsc.32.7.841.

Sheail, J. (1984). Constraints on water-resource development in England and Wales: The concept and management of compensation flows. J. Environ. Manage., 19(4), 351-361.

Shen, J., Huang, G.H., An, C.J., Xin, X.Y., Huang, C., and Rosendahl, S. (2018). Removal of tetrabromobisphenol a by adsorption on pinecone-derived activated charcoals: Synchrotron FTIR, kinetics and surface functionality analyses. Bioresour. Technol., 247, 812-820. https://doi.org/10.1016/j.biortech.2017.09.177

Smakhtin, V. (2008). Basin closure and environmental flow requirements. International J. Water Resour. Dev., 24(2), 227-233. http:// dx.doi.org/10.1080/07900620701723729

Stalnaker, C.B., Lamb, B.L., Henriksen, J., Bovee, K.D., and Bartholow, J. (1994). The instream flow incremental methodology: a primer for IFIM, National Ecology Research Center, Fort Collins, International Publication, Colorado.

Sun, T., Zhang, H., Yang, Z., and Yang, W. (2015). Environmental flow assessments for transformed estuaries. J. Hydrol., 520, 75-84. http://dx.doi.org/10.1016/j.jhydrol.2014.11.015

Tennant, D. L. (1976). Instream flow regimens for fish, wildlife, recreation and related environmental resources. Fish., 1(4), 6-10. http://dx.doi.org/10.1577/1548-8446(1976)001<0006:IFRFFW $>2$. $0 . \mathrm{CO} ; 2$

Tharme, R.E. (2003). A global perspective on environmental flow assessment: emerging trends in the development and application of environmental flow methodologies for rivers. River Res. Appl., 19(5-6), 397-441. http://dx.doi.org/10.1002/rra.736

Thoms, M.C., Sheldon, F., Roberts, J., Harris, J., and Hillman, T.J. (1996). Scientific panel assessment of environmental flows for the Barwon-Darling River, NSW Department of Land and Water Conservation, Sydney.

Vorosmarty, C.J., Green, P., Salisbury, J., and Lammers, R.B. (2000). Global water resources: Vulnerability from climate change and population growth. Science, 289(5477), 284-288. http://dx.doi.org/ $10.1126 /$ science. 289.5477 .284

Wang, L., Huang, G.H., Wang, X.Q., and Zhu, H. (2018). Risk-based electric power system planning for climate change mitigation through multi-stage joint-probabilistic left-hand-side chance-constrained fractional programming: A Canadian case study. Renew. Sust. Energ. Rev., 82(1), 1056-1067. https://doi.org/10.1016/j.rser.2017.09. 098
Wright, J.F., Furse, M.T., and Moss, D. (1998). River classification using invertebrates: RIVPACS applications. Aquat. Conserv.: Mar. Freshw. Ecosyst., 8(4), 617-631. http://dx.doi. org/10.1002/(SICI) 1099-0755(199807/08)8:4<617::AID-AQC255>3.0.CO;2-\#

Wu, C.B., Huang, G.H., Xin, B.G., and Chen, J.K. (2018). Scenario analysis of carbon emissions' anti-driving effect on Qingdao's energy structure adjustment with an optimization model, Part I: Carbon emissions peak value prediction. J. Clean. Prod., 172, 466474. https://doi.org/10.1016/j.jclepro.2017.10.216

Ye, Z.X., Chen, Y.N., and Li, W.H. (2010). Ecological water demand of natural vegetation in the lower Tarim River. J. Geogr. Sci., 20(2), 261-272. http://dx.doi.org/10.1007/s11442-010-0261-3

Yu, F.K., Huang, X.H., Liang, Q.B., Yao, P., Li, X.Y., Liao, Z.Y., Duan, C.Q., Zhang, G.S., and Shao, H.B. (2015). Ecological water demand of regional vegetation: The example of the 2010 severe drought in Southwest China. Plant Biosyst., 149(1), 100-110. http://dx.doi.org/10.1080/11263504.2013.817488

Yu X.X., and Chen, L.H. (1996). A study on water balance of protective forest ecosystem in Loess area. Acta Ecol. Sin., 16(3), 238-245. (in Chinese)

Zalewski, M. (2000). Ecohydrology-the scientific background to use ecosystem properties as management tools toward sustainability of water resources. Ecol. Eng., 16(1), 1-8. http://dx.doi.org/10.1016/ S0925-8574(00)00071-9

Zalewski, M. (2015). Ecohydrology and hydrologic engineering: regulation of hydrology-biota interactions for sustainability. J. Hydrol. Eng., 20(1). http://dx.doi.org/10.1061/(asce)he.1943-5584.00 00999

Zhao, W.Z., Chang X.L., He Z.B., and Zhang Z.H. (2007). Study on vegetation ecological water requirement in Ejina Oasis. Sci. China Ser. D (Earth Sci.), 50(1), 121-129. http://dx.doi.org/10.1007/s11 430-007-2035-z

Zhao, X., Chen, B., and Yang, Z.F. (2009). National water footprint in an input-output framework - A case study of China 2002. Ecol. Model., 220(2), 245-253. https://doi.org/10.1016/j.ecolmodel.2008. 09. 016

Zhao, X., Yang, H., Yang, Z.F., Chen, B., and Qin, Y. (2010). Applying the input-output method to account for water footprint and virtual water trade in the Haihe River Basin in China. Environ. Sci. Technol., 44(23), 9150-9156. http://dx.doi.org/10.1021/es100886r 